DOI: https://doi.org/10.24867/05EF05Devai

\title{
ANALIZA KVALITETA OTISAKA DOBIJENIH POSTUPKOM ELEKTROGRAFIJE NA GRAFIČKOM SISTEMU KONICA MINOLTA C6000L
}

\section{ANALYSIS OF THE QUALITY OF FEATURES PROVIDED BY THE ELECTROGRAFIC PROCESS AT THE GRAPHIC SYSTEM KONICA MINOLTA C6000L}

\author{
Stefan Devai, Nemanja Kašiković, Ana Lilić, Fakultet tehničkih nauka, Novi Sad
}

\section{Oblast - GRAFIČKO INŽENJERSTVO I DIZAJN}

Kratak sadržaj- $U$ okviru rada predstavljena su istraživanja iz oblasti digitalne tehnike štampeelektrografija. Za otiskivanje je korišćen grafički sistem Konica Minolta C6000L. Za potrebe ovog istraživanja kreirana je test karta, koja je odštampana na tri podloge različite gramature $150 \mathrm{~g} / \mathrm{m}^{2}, 200 \mathrm{~g} / \mathrm{m}^{2}$ i $300 \mathrm{~g} / \mathrm{m}^{2}$, zatim su izvršena merenja beline $i$ žutoće papira, optičkih gustina, porast tonskih vrednosti, Lab vrednosti $i$ spektralna refleksija polja na test karti. Rezultati rada su prikazani pomoću grafika, nakon čega je izvršeno analiziranje $i$ upoređivanje dobijenih rezultata. Cilj istraživanja je izračunavanje razlike $u$ boji, čijom analizom je kasnije utvrđen kvalitet ponovljivosti štampe. Takođe, vršena je analiza vremenske $i$ prostorne ponovljivosti.

Ključne reči: digitalna štampa, elektografija, ponovljivost štampe.

Abstract- The paper presents research in the field of digital technique of press-electrography. For printing, the Konica Minolta C6000L graphic system was used. For the purposes of this research, a test card was created, which was printed on three substrates of different grammes of $150 \mathrm{~g} / \mathrm{m}^{2}, 200 \mathrm{~g} / \mathrm{m}^{2}$ and $300 \mathrm{~g} / \mathrm{m}^{2}$, followed by white and yellow paper measurements, optical densities, increase in tonal values, Lab values $i$ spectral field reflection on the test map. The results of the work are shown using graphics, followed by analyzing and comparing the results obtained. The aim of the study is to calculate the color difference, whose analysis later determined the quality of the repeatability of the printing. Also, an analysis of time and spatial repeatability was performed.

Keywords: digital printing, electrography, print repetition.

\section{UVOD}

Digitalna štampa dobija sve veći značaj zbog mogućnosti štampe velikog broja proizvoda jer je nemoguće proizvesti konvencionalnim tehnikama ili je moguće, ali nije isplativo.

To su izrada malih formata, štampa na zahtev, personalizacija i druge.

\section{NAPOMENA:}

Ovaj rad proistekao je iz master rada čiji mentor je bio dr Nemanja Kašiković, vanred. prof.
Pored toga, omogućeno je brže obavljanje posla čime se dobija visok kvalitet po pristupačnoj ceni. Skraćivanje vremena proizvodnje omogućeno je zahvaljujući stalnom razvoju računarskih tehnologija koje mogu obaviti složene operacije kao što su izrada i montaža štamparskih formi i priprema mašine koje bi kod konvencionalnih tehnika izveo operater.

Zajedno sa tehnološkim napretkom industrije i razvojem računara, razvijala se tehnologija štampe čiji su počeci vezani za pojavu prvog kancelarijskog štampača. Digitalna štampa je najnovija tehnika štampe, ali istovremeno i najnaprednija. Uporedo sa automatizacijom procesa rada, digitalna štampa se neprestano razvija i polako preuzima primat među drugim tehnikama štampe. Njena prednost je brzina i mogućnost promene podataka bez uticaja na tiraž i zbog toga nju često nazivaju Printing on Demand [1].

Elektrografija je jedna od glavnih tehnika digitalne štampe. Kod ovog procesa štampe jedinstvena virtuelna štamparska forma nastaje tokom Non Impact štamparskog procesa na površini fotokonduktora. Pri svakom ciklusu štampanja štamparska slika se prenosi ponovo na štamparsku formu [2].

Jedna od bitinih stvari u svim procesima štampe je ponovoljivost kvaliteta otiska. Upravo zbog toga je postavljen cilj istraživanja, a to je da se izračunaju razlike $\mathrm{u}$ boji, čijom analizom se kasnije utvrđuje kvalitet ponovljivosti štampe. Takođe, vršena je analiza vremenske i prostorne ponovljivosti.

\section{METOD IZVOĐENJA EKSPERIMENTA}

Za potrebe ovog istraživanja kreirana je test karta, koja je odštampana na tri podloge različite gramature $150 \mathrm{~g} / \mathrm{m}^{2}$, $200 \mathrm{~g} / \mathrm{m}^{2}$ i $300 \mathrm{~g} / \mathrm{m}^{2}$, zatim su izvršena merenja beline i žutoće papira, optičkih gustina, porast tonskih vrednosti, Lab vrednosti i spektralna refleksija polja na test karti. Rezultati rada su prikazani pomoću grafika, nakon čega je izvršeno analiziranje i upoređivanje dobijenih rezultata. Test karta koja je korišćena u eksperimentu prikazana je na slici 1.

Uzorci za potrebe ovog istraživanja su odštampani na mašini Konica Minolta C6000L koja radi na principu elektrografije [3]. Štampanje uzoraka vršeno je u tri vremenska intervala: na početku štampe, posle jednog časa i nakon dvadeset četiri časa od početka štampe.

Merenje svih parametara vršeno je pomoću spektrofotometra SpektroDens, marke Techikon. Korišćeni uređaj (osvetljenje D50, standardni posmatrač $2^{\circ}$, merna geomet- 
rija $0^{\circ} / 45^{\circ}$, merni otvor $3 \mathrm{~mm}$ ) predstavlja refleksioni spektrometar sa mogućnošću izračunavanja spektralnih, kolorimetrijskih i denziometrijskih veličina.

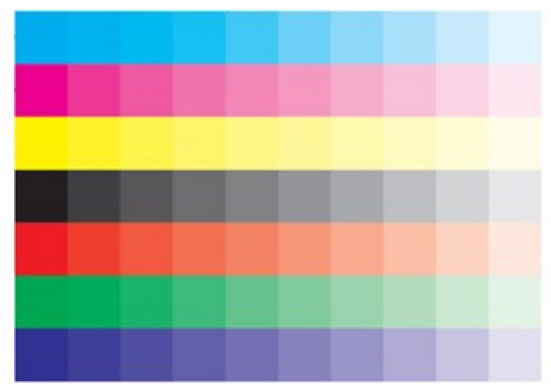

Slika 1. Test karta

\section{REZULTATI RADA SA DISKUSIJOM}

Zbog velikog broja rezultata koji su dobijeni prilikom ovog istraživanja, u ovom radu biće samo neki prikazani. Biće predstavljeni dobijeni rezultati parametara za belinu i žutoću papira, optičku gustinu i porast tonskih vrednosti.

\subsection{Belina i žutoća}

Merenje beline i žutoće izvršeno je na belom delu papira. Svaki uzorak izmeren je 4 puta na osnovu dobijenih rezultata izračunate su srednje vrednosti i grafički prikazane. $\mathrm{Na}$ grafiku 1. prikazane su vrednosti beline $\mathrm{i}$ žutoće.

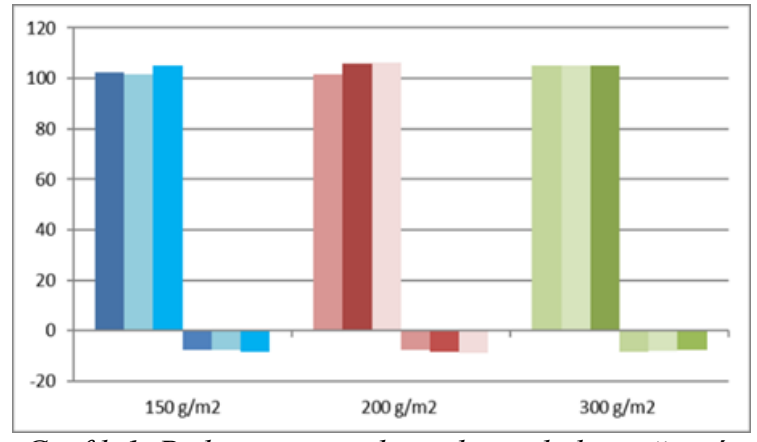

Grafik 1. Prikaz izmerenih vrednosti beline i žutoće

Za ispitivanje ovog parametra korišćeni su uzorci: prvi uzorak na početku štampe, drugi uzorak posle jednog časa $\mathrm{u}$ odnosu na prvi uzorak i treći uzorak nakon dvadeset četiri časa u odnosu na prvi odštampani uzorak. Na osnovu dobijenih rezultata možemo videti da postoje veoma mala odstupanja između vrednosti beline i žutoće papira iste gramature, na osnovu čega se zaključuje da je konstantnost rezultata veoma dobra.

\subsection{Optička gustina}

Merenje optičke gustine vršeno je na polju punog tona za sve 4 procesne boje. $\mathrm{Na}$ svakom uzorku izvršena su tri merenja na različitim mestima podloge. $\mathrm{Na}$ osnovu dobijenih rezultata izračunate su srednje vrednosti i grafički prikazane, tako da svaki grafik predstavlja jednu vrstu materijala.

$\mathrm{Na}$ grafiku 2. predstavljene su optičke gustina papira gramature $150 \mathrm{~g} / \mathrm{m}^{2}$ nakon prvog štampanja, posle $1 \mathrm{~h} \mathrm{i}$ nakon $24 \mathrm{~h}$ od prvog štampanja.

Na grafiku 2. zaključuje se da vrednosti optičke gustine ne variraju znatno u toku vremena. Najmanje oscilacije se primećuju kod cijana i žute boje, gde su optičke gustine identične, dok je najveća razlika u vrednostima zapažena kod magente.

$\mathrm{Na}$ grafiku 3. predstavljene su optičke gustine papira gramature $200 \mathrm{~g} / \mathrm{m}^{2}$ nakon prvog štampanja, posle $1 \mathrm{~h} \mathrm{i}$ nakon $24 \mathrm{~h}$ od prvog štampanja.

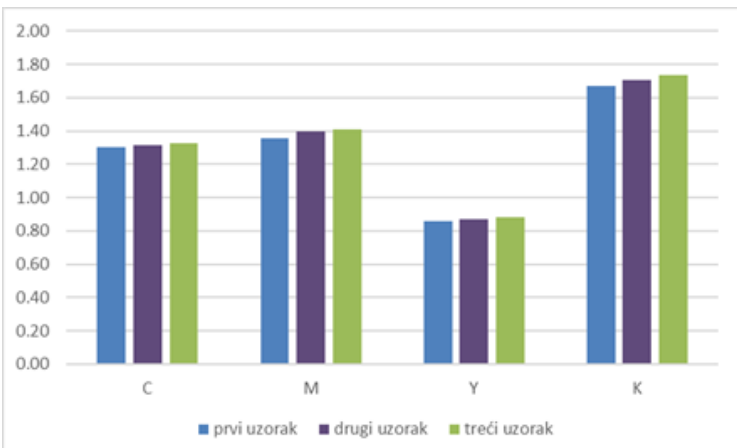

Grafik 2. Optičke gustine papira gramature $150 \mathrm{~g} / \mathrm{m}^{2}$

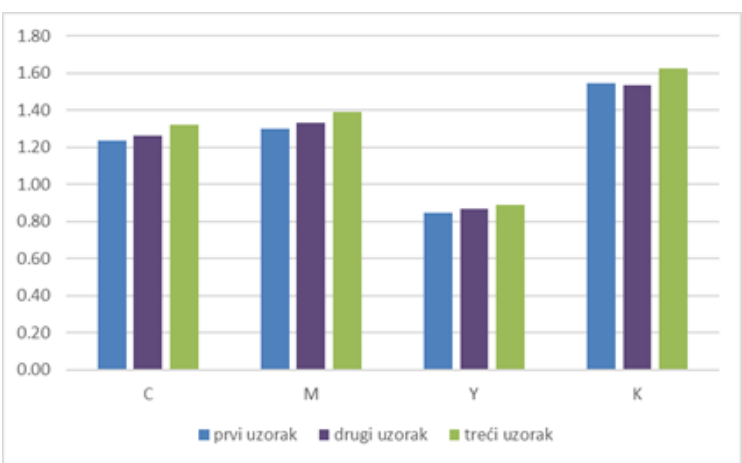

Grafik 3. Optičke gustine papira gramature $200 \mathrm{~g} / \mathrm{m}^{2}$

Iz grafika 3. zaključujemo da se vrednosti optičke gustine konstantno povećavaju. Kod žute boje povećanje je najmanje, dok kod crne boje najveće. Takođe, može se primetiti da sve optičke vrednosti prelaze vrednost $1 \mathrm{sem}$ žute boje. Ponovljivost vrednosti optičke gustine je zadovoljavajuća i u dozvoljenim granicama je kod ovog uzorka.

$\mathrm{Na}$ grafiku 4. predstavljene su optičke gustine papira gramature $300 \mathrm{~g} / \mathrm{m}^{2}$ nakon prvog štampanja, posle $1 \mathrm{~h} \mathrm{i}$ nakon $24 \mathrm{~h}$ od prvog štampanja.

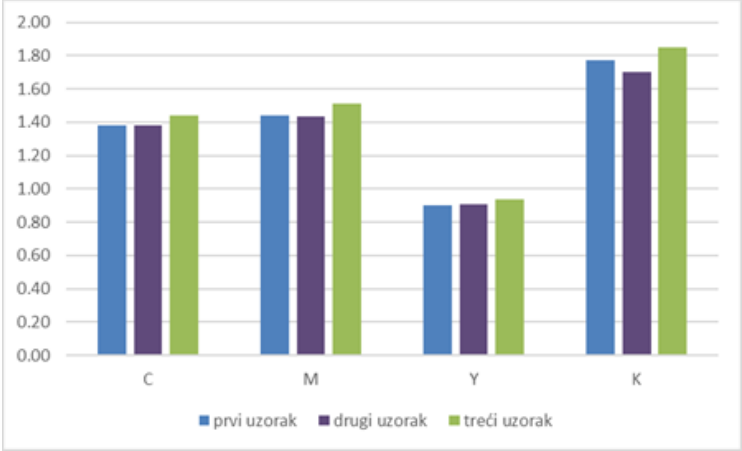

Grafik 4. Optičke gustine papira gramature $300 \mathrm{~g} / \mathrm{m}^{2}$

$\mathrm{Na}$ osnovu rezultata iz grafika 4. zaključuje se da su vrednosti optičke gustine nakon $1 \mathrm{~h}$ od prvog štampanja ostaju identične (sem kod crne boje), a da nakon štampe posle $24 \mathrm{~h}$ rastu.

Najveću razliku postigla je crna boja, dok najmanju ima žuta boja. Kod ovog uzorka primećuje se da je najveća oscilacija optičke gustine u toku vremena. 


\subsection{Tonska vrednost}

Za merenje tonske vrednosti koriste se polja od 10-90\% na CMYK poljima. Proces merenja ponovljen je 3 puta za svaki pojedinačni uzorak. Nakon merenja izračunata je srednja vrednost za svaki uzorak, a rezultati su prikazani pomoću grafika. Svaki grafik predstavlja određeni procenat tonske vrednosti, gde su redom predstavljeni uzorci po gramaturi i redosledu štampanja.

$\mathrm{Na}$ graficima od 5 do 13 prikazane su tonske vrednosti na CMYK poljima.

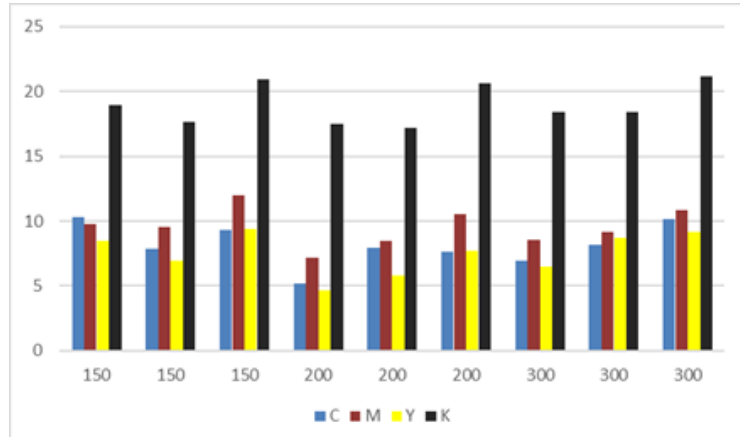

Grafik 5. Raster tonska vrednost od $10 \%$ nakon prvog štampanja, nakon $1 \mathrm{~h}$ i nakon $24 \mathrm{~h}$

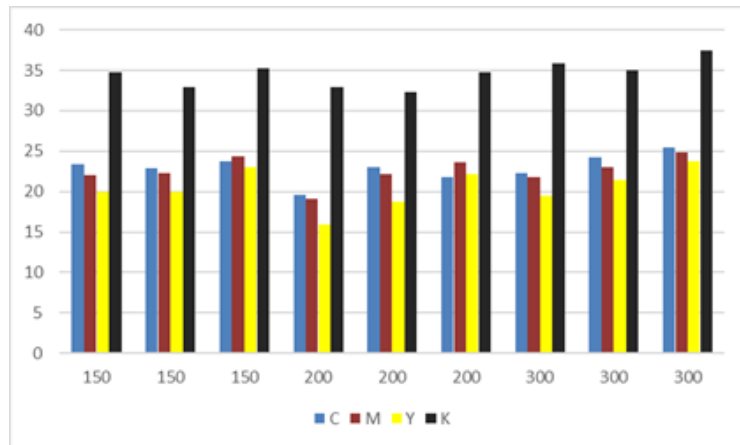

Grafik 6. Raster tonska vrednost od $20 \%$ nakon prvog štampanja, nakon $1 \mathrm{~h}$ i nakon $24 \mathrm{~h}$

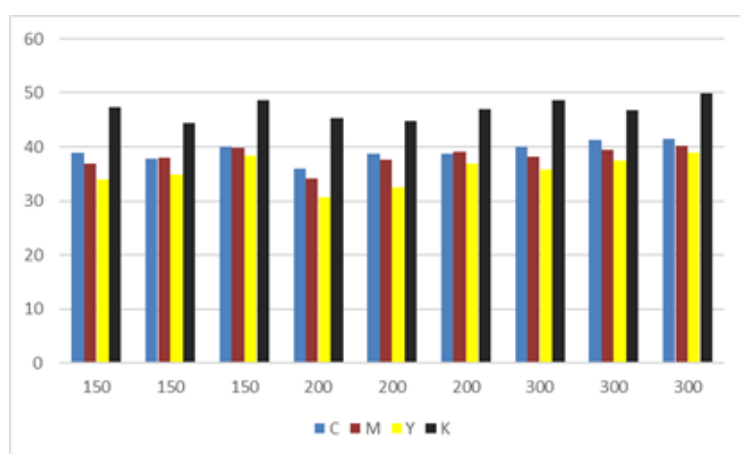

Grafik 7. Raster tonska vrednost od $30 \%$ nakon prvog štampanja, nakon $1 \mathrm{~h}$ i nakon $24 \mathrm{~h}$

$\mathrm{Na}$ osnovu vrednosti prikazanih na graficima, najveću vrednost ima crna boja, dok kod cijana, magente i žute boje postoje minimalne oscilacije.

Kod uzorka gramature $150 \mathrm{~g} / \mathrm{m}^{2}$ može se primeti da postoji minimalna oscilacija između uzoraka. Osim kod vrednosti $50 \%$ gde se prvi uzorak nezntano razlikuje od druga dva koja su identična.

Kod drugog uzorka pri vrednosti od $60 \%$ zabeležen je blagi porast crne boje, dok je pri vrednosti $80 \%$ zabeležena najveća razlika između magente i crne boje, zatim kod vrednosti od $90 \%$ zabeležen je porast žute boje.

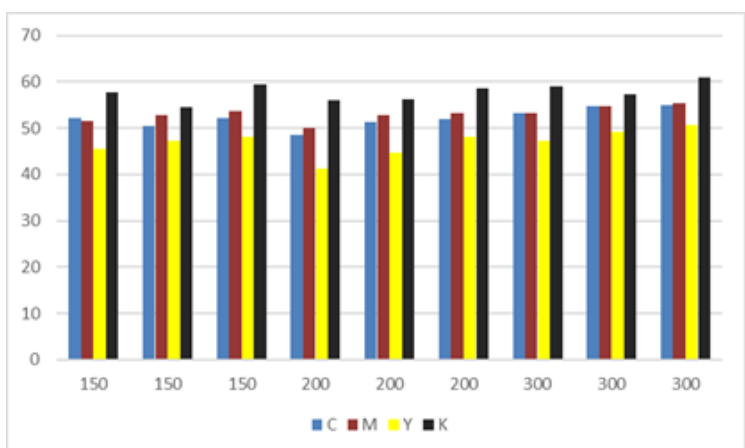

Grafik 8. Raster tonska vrednost od $40 \%$ nakon prvog štampanja, nakon $1 \mathrm{~h}$ i nakon $24 \mathrm{~h}$

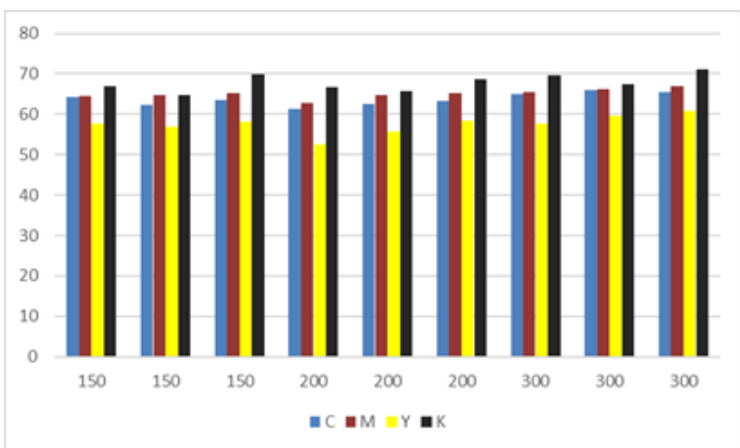

Grafik 9. Raster tonska vrednost od 50\% nakon prvog štampanja, nakon $1 \mathrm{~h}$ i nakon $24 \mathrm{~h}$

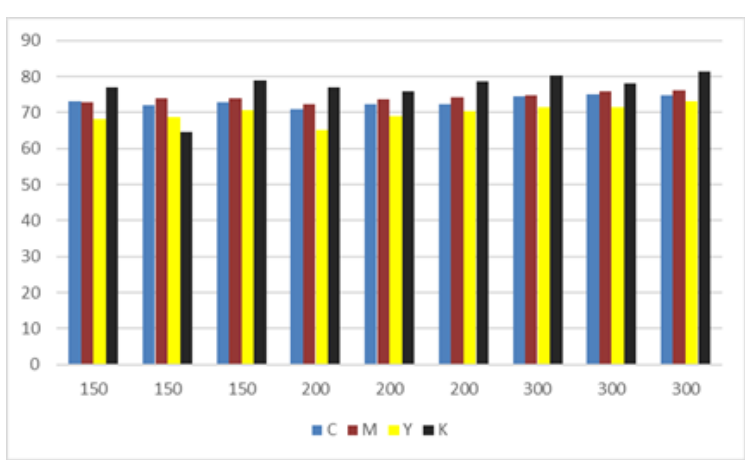

Grafik 10. Raster tonska vrednost od $60 \%$ nakon prvog štampanja, nakon $1 \mathrm{~h}$ i nakon $24 \mathrm{~h}$

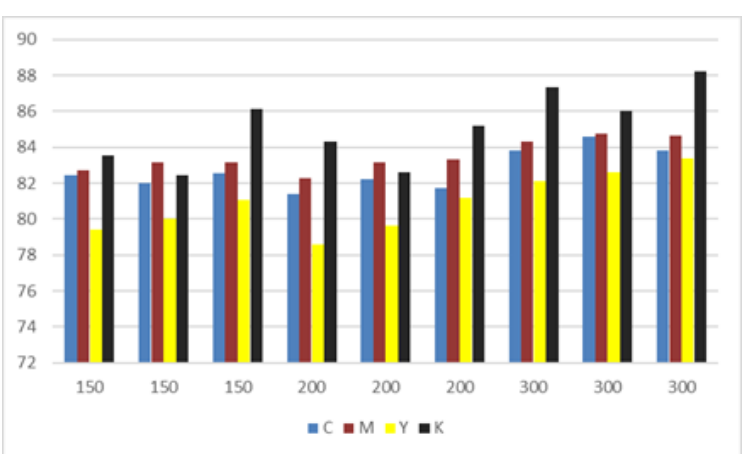

Grafik 11. Raster tonska vrednost od $70 \%$ nakon prvog štampanja, nakon $1 \mathrm{~h}$ i nakon $24 \mathrm{~h}$

Kod trećeg uzorka pri vrednosti od $70 \%$ zabeležen je blagi porast crne boje. Kod uzorka gramature $200 \mathrm{~g} / \mathrm{m}^{2}$ vrednost cijana, magente žute boje je u blagom porastu dok najveću vrednost ima crna boja. Kod vrednosti od $70 \%$ možemo primetiti blagi porast žute boje, a blagi pad kod crne. Kod vrednosti od $80 \%$. može se primetiti da cijan i žuta boja imaju jednake vrednosti. Kod uzorka gramature $300 \mathrm{~g} / \mathrm{m}^{2}$ za sva tri uzorka rezultati tonskih 
vrednosti pojavljuju se minimalne oscilacije, ali najveći porast ima crna boja.

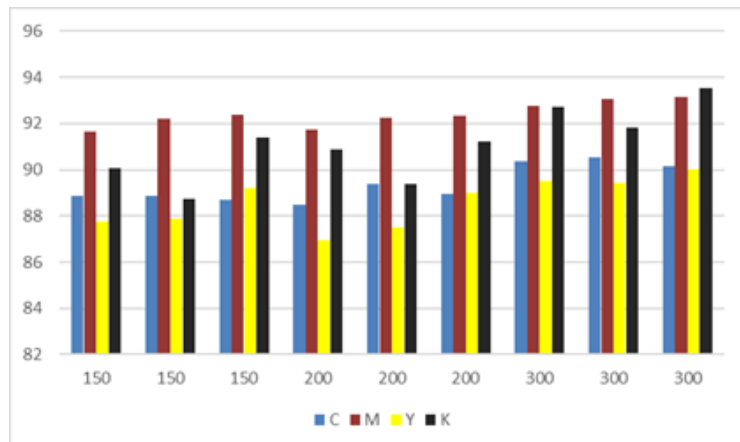

Grafik 12. Raster tonska vrednost od $80 \%$ nakon prvog štampanja, nakon $1 \mathrm{~h}$ i nakon $24 \mathrm{~h}$

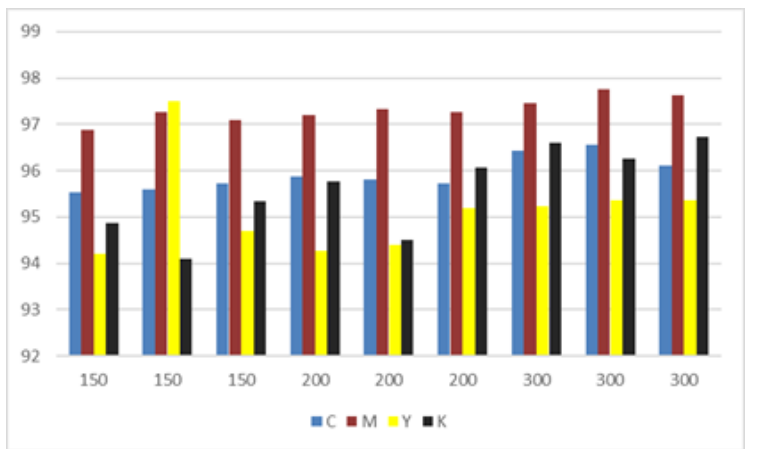

Grafik 13. Raster tonska vrednost od 90\% nakon prvog štampanja, nakon $1 \mathrm{~h}$ i nakon $24 \mathrm{~h}$

\section{ZAKLJUČAK}

Konstantno razvijanje tehnika u grafičkoj industriji nameće i potrebu za razvijanjem procesa kontrole odštampanih otisaka. Trenutno je digitalna štampa tehnika koja je $\mathrm{u}$ intenzivnom i svakodnevnom porastu. Iz tog razloga, otisci koji su korišćeni u ovom radu štampani su elektrofotografijom.
Sa osvrtom na rezultate došli smo do zaključka da se može primetiti razlika u odnosu na koji materijal se štampa. Materijal gde je kvalitet bio najmanje promenljiv jeste papir gramature $300 \mathrm{~g} / \mathrm{m}^{2}$, kod papira gramatura od $150 \mathrm{~g} / \mathrm{m}^{2}$ i $200 \mathrm{~g} / \mathrm{m}^{2}$ uglavnom se primećivala razlika između drugog i trećeg odštampanog uzorka u odnosu na prvi. Ovakve razlike mogu se smanjiti sa redovnim kalibrisanjem i podešavanjem štamparskog sistema.

\section{LITERATURA}

[1] Novaković, N., Pavlović, Ž., Kašiković, N. (2015) Tehnike štampe: priručnik za vežbe. Novi

Sad, FTN Izdavaštvo

[2] Novaković, D., Kašiković, N. (2013) Digitalna štampa. Novi Sad, FTN izdavaštvo

[3] Konica Minolta (2012) Bizhub PRO C6000L [Online] Dostupno na: https://vipimex.com/

files/files/bizhub_PRO_C6000L_General_Brochure.pdf [Pristupljeno 07.06.2019]

\section{Podaci za kontakt:}

Stefan Devai stefan.devai@gmail.com Nemanja Kašiković knemanja@uns.ac.rs Ana Lilić lilic.ana@uns.ac.rs 